\title{
Determinants Of Accounting Anxiety In Business Students
}

Charles A. Malgwi (E-mail: cmalgwi@bentley.edu), Bentley College

\begin{abstract}
The identification of the level of anxiety, especially in accounting among business students, have not been directly explored and recognized. This empirical study was conducted to ascertain any significant determinants of accounting anxiety among business students. An online survey questionnaire was administered to all registered students at Bentley College, the largest business University in New England. A new accounting anxiety rating scale (AARS) was developed based on a modified computer anxiety rating scale (CARS) by Broome and Havelka (2002). A total of 1,112 responses were received and analyzed, indicating a response rate of 30 percent, which is relatively significant considering similar online survey responses. ANOVA tests were applied to determine the significance in accounting anxiety, controlling for four variables, academic majors, degree levels, experience and gender. The results show that there are significant differences in accounting anxiety levels in all four tests among students with different academic majors, degree levels, work experiences and significant difference in accounting anxiety between male and female students, contrary to recent and similar study of computer anxiety in business students.
\end{abstract}

\section{Introduction}

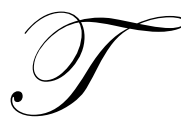

here have been several clarion calls and studies on why accounting as a profession is experiencing a declining trend. The pedagogical nuances and fall in enrollments among college students as accounting majors, especially in business schools, is of major concern. For example, prior studies suggest that accounting is generally regarded as a high-risk course that is characterized by high failure and withdrawal rates (Widmar 1994; Etter et al. 2000). Similar studies (Albecht and Sack 2000; AECC 1996; and Arendale 1994) came up with the same concern and called for ways to make introductory accounting courses more attractive in order to encourage and motivate students to become accounting majors. What is not clear, however, is where the problem lies. Many researchers (e.g., Williams 1991; Baldwin and Ingram 1991) attributed the accounting problem to: not attracting sufficient numbers of students of sufficient quality; the accounting curriculum has lost its relevance; not sufficiently developing the skills and attributes of students; not demonstrating to students why the information is important; and how the resulting information can be used. With the relatively recent publicity about accounting scandals following Enron and WorldCom, among others, there seem to be a comeback among business students majoring in accounting. Similarly, the new prominence accorded to and demand for internal auditors as required by the Sarbanes-Oxley Act of 2002 has contributed to the increase among business students as accounting majors.

The end to the declining trend in accounting majors notwithstanding, students' perception of a desired course of study could be different from their interest in that subject. Therefore, many similar disciplines have considered such problems differently. For example, researchers have looked at anxiety as one of the major hindrances to academic performance. For instance, anxiety studies have been carried out in disciplines such as computers, mathematics, chemistry, and medicine. The author is not aware of such a study directly related to accounting as an information system among business students. The closest anxiety study in accounting is the one about teaching anxiety among accounting educators (Ameen et al. 2002).

Anxiety has been defined in the context in which it is used. For example, studies about anxiety among computer, math and chemistry students define anxiety respectively, as the fear of computers when using the computer or when considering the possibility of computer use (Heinssen et al. 1987). Venkatesh (2000), noted, too 
that computer anxiety affects the way individuals view a specific software package and their use of that software. Mathematics anxiety has also been defined as an "irrational dread of mathematics that interferes with manipulating numbers and solving mathematical problems within a variety of everyday life and academic situations" (Buckley and Ribordy 1982, 1). In chemistry laboratory, anxiety is not defined, but referred to it from a cognitive (worry) perspective, which hinders students' performance in chemistry laboratory, especially on understanding of chemical concepts, use of reasoning skills, and laboratory skills (Bowen 1999).

From the foregoing definitions and in the absence of any accounting anxiety definition known to the author, accounting anxiety may be defined, for the purpose of this research, as the individual's apprehension or fear of accounting in terms of comprehending accounting concepts, applying economic events by completing the accounting cycle, preparing the final accounts, interpreting, analyzing, and communicating the financial information useful for decision making purposes. This definition includes the apprehension or fear of utilizing applicable accounting software, sitting for the certified public accountants (CPA) exams and the risk of committing a grave mistake, which could be interpreted as gross negligence and lack of professional competence.

The motivation of this study comes from Broome and Havelka's (2002) paper, where they looked at the determinants of computer anxiety in business students. They called for and encouraged similar study in other professions. Secondly, even though lately there has been a growing interest in accounting in general, such growth is still relatively lower that what it used to be some years back at this business college. Part of the motivation is to ascertain if such a decline is attributed to accounting anxiety where majority of business students are choosing academic majors other than accounting in one of the largest business universities in New England. The purpose of the research, therefore, is to identify if accounting anxiety is a matter of concern among business students, and if so, such anxiety may cause the development of learning behaviors that are inappropriate, ineffective, and damaging to the students' health (see also Ameen et al. 2002). An early detection would serve as a guide for further study that would help accounting educators to address it at an early stage. This would help business students, irrespective of their major to see the value of and appreciation for accounting as an information system in relation to its real-life application, connections to other disciplines, existence in other cultures, use as a tool for learning, and characteristics as a language of business (also see National Council of Teachers of Mathematics 1989, 233 and Furner and Berman 2003). It is also essential to acknowledge that reducing anxiety would potentially enhance learning and motivate students to becoming accounting majors.

The remaining paper is divided into three sections. The first section reviews related literature and presents the development of hypotheses. The second section focuses on the methods used in gathering the data and presentation of the results. The final section discusses the implications of the findings for improving research and practice in accounting education.

\section{Review Of Prior Research And Hypotheses Development}

One of the common aspects of calls for change in accounting education centers on knowledge and skill that is related to information technology, computing and accounting systems. For example, the Accounting Education Change Commission's (AECC) Position Statement Number One (1990) identified the "design and use of information technology" as a core dimension of basic accounting education. However, Stone, Arunachalam and Chandler (1996) had earlier examined the cross-cultural comparisons on knowledge, skill, self-efficacy and computer anxiety in accounting education and found that spreadsheet, database and computer self-efficacy may be more relevant to accounting education than computer anxiety measures. Their study also contends that measures of self-efficacy may be increasingly useful as diagnostic tools as accounting education places more emphasis on skills relative to knowledge. While the findings of these four attributes (knowledge, skill, self-efficacy and computer) provide useful information relating to anxiety in accounting education, the idea of whether the accounting subject itself causes anxiety among business students is still lacking. 


\subsection{Anxiety}

Determinants creating anxiety consist of a variety of issues and are largely dependent upon the subject matter. The emphasis placed on accounting educators to embrace the use of technology makes accounting and technology more comparable. For example, earlier research in computer anxiety is associated with different types of learning styles (Bozionelos 1997a). Therefore, in order to increase the performance of such students, it would require a different type of training or human-computer interfaces to reduce computer anxiety (Broome and Havelka 2002). Also, studies show that even among individuals who may share similar cultural upbringings, determinants such as gender and background experience may play an important role (McIlory et al. 2001). Similarly, anxiety is most often seen in mathematics courses required for non-technical majors (Fairbanks 1992). The same observation perhaps is true in accounting for non-accounting majors. On a more general note, other researchers contend that one of the factors creating anxiety is ineffective time management strategies and lack of productive study methods (Cambell and Svenson 1992). Like stress, academic anxiety includes the student's perception of the extensive knowledge base required and the perception of the inadequate time to develop it (Carveth et al. 1996). Some of the sources of such anxiety result from taking and studying for exams, grade competition, and the large amount of content to master in a small amount of time (Britton and Tesser 1991; and Abouserie 1994).

While Chu and Spires (1991) reported that most research see anxiety as an issue that can be treated rather than as an inherent emotion (state anxiety), others like Preiss, Wheeless and Allen (1990) reported on a metaanalysis explaining the association between receiver apprehension and various cognitive processes of anxiety. Their findings are relevant to this study, particularly when it was reported that receiver apprehension has an average correlation of -.59 with information processing effectiveness. This suggests that, as receiver apprehension increases, participation performance on reasoning tasks, comparative judgments, and inferential judgments decreases. Identifying the determinants of accounting anxiety would, therefore, help the AECC, educators, and managers to structure learning and training that would minimize the cognitive nature of accounting anxiety.

\subsection{Cognitive Anxiety}

Observing from a cognitive perspective, it is appropriately logical to acknowledge that anxiety can have an adverse or negative effect on student's learning and performance. For example, the model constructed by Humphreys and Revelle (1984) linking individual differences to information processing, suggest that anxiety can either enhance or reduce quality of performance based on the nature of the task. As a result, they envisioned that high anxiety facilitates performance on easy tasks or when the feedback is positive. Thus, high anxiety hinders performance on difficult tasks or when the feedback is negative. They further explained that there is some evidence that the relative contributions of the cognitive (worry) and somatic (arousal) components change as tasks change (Humphreys and Revelle, 1984, 175).

It appears likely that students studying accounting, accounting information systems, corporate finance \& accounting, and finance, will possess no significant levels of accounting anxiety due to the level and degree of exposure that they may have to a variety of accounting courses, their experience through internships, and using accounting software programs. However, Towell and Lauer (2001) contend in their study of computer related stress in business students that those who work regularly with technology will show higher levels of computer anxiety for the simple reason that they must work with technology more often. In other words, they are more apprehensive since they can't avoid working with the computer.

Also, other studies show that students have different levels of anxiety and would, therefore, perform differently when asked to use, for example, computers to perform a task (see Burkett et al. 2001). As a result of this, it is essential for this study to ascertain if differences among students with different disciplines exist. Determination of such differences is important for prescriptive purposes that could be used by both faculty and administrators to reduce accounting anxiety among those identified with significant anxiety problems. Given the findings of prior research relating to anxiety, coupled with the objectives of this research, an alternative form of the first hypothesis is given for test purposes as: 
H1: There are higher accounting anxieties among business students majoring in less quantitative degree majors than those in more quantitative degree majors.

Hypothesis 1 is consistent with similar studies, especially when one looks at prior research of this kind where anxiety levels across dividing lines exist (Rosen and Weil 1995 and Todman 2000). Therefore, the determination of whether or not business students within different academic disciplines display differences in accounting anxiety are essential.

It is perhaps logical to assume that since experience is expected to reduce the level of anxiety among students, their level of academic experience, i.e., degree levels (freshmen, sophomores, juniors, seniors and graduates) should be relatively comparable to years of experience in reducing anxiety levels because of the number of accounting courses taken. In other words, one would expect to see lower levels of accounting anxiety among upper degree levels, such as graduates and seniors, than among freshmen and sophomore business students. Therefore hypothesis two is stated as:

H2: There are higher accounting anxieties in students at their lower degree levels (i.e., freshmen and sophomore) than those at their upper (i.e., junior, senior and graduate) degree levels.

There are several studies that have looked at the relationship between anxiety and work experience (also stress, experience, and job performance) and came up with conflicting results. For example, strong arguments have surfaced in support of a negative relationship between job performance and both role conflict and role ambiguity (Fisher 2001). For instance, Jackson and Schuler (1985, 42-43) argued, "from a cognitive perspective, performance should be hindered by role ambiguity and role conflict because with them the individual faces either a lack of knowledge about the most effective behaviors to engage in or an almost impossible situation for doing everything expected. Therefore, regardless of the amount of effort expended behaviors are most likely to be inefficient, misdirected, or insufficient." This study considers experience to be a learning curve, where the more familiar one is with doing a particular task, the less likely that that individual would experience anxiety. This is because the task becomes intuitive and more mechanical and, therefore, reduces the likelihood of anxiousness.

Since anxiety can be treated as noted earlier in Chu and Spires (1991), accounting experience or exposure should, therefore, help reduce the level of anxiety among students who possess that experience and exposure. In order to investigate the relationship between accounting experience and accounting anxiety levels, it is expected that students who had more years of experience would have lower levels of accounting anxiety. This then leads to the third hypothesis:

H3: There are higher accounting anxieties among business students with less years of work experience or exposure than those with more work experience or exposure.

Evidences exist in previous researches that show conflicting gender differences in anxiety, especially computer anxiety. For example, women are shown to experience higher levels of negative consequences and computer anxiety in the workplace than men do (Todman 2000 and Mcllroy et al. 2001). However, Broome and Havelka's (2002) study in the same computer anxiety show men, and not women, that have higher levels of computer anxiety. Also, an earlier study by Rosen and Weil (1995) show gender differences in computer anxiety between men and women and also among students of different nationalities. As there are more female than male students at this business college, it suggests that female students are equally up to the task, if not more, in competing with their male counterparts. This study therefore explores the likelihood of any significant gender differences in accounting anxiety between business students relative to previous studies. Thus, hypothesis four tests the significance of accounting anxiety between male and female as follows:

H4: There are lower levels of accounting anxiety in female than in male business students.

An empirical investigation was performed to test all four hypotheses. The survey instrument used and the data collected is discussed in the next section. 


\section{Methodology and Research Design}

\subsection{Survey Instrument}

The survey instrument used in this study is a model (for the accounting anxiety) called the Accounting Anxiety Rating Scale (AARS). It is a model coined after the Computer Anxiety Rating Scale (CARS) originally developed by Heinssen, et al. in 1978 (see Heinssen, et al., 1978), which was then validated by Chu and Spires (1991). The development of CARS was well received and applauded by many researchers both in academics and in the corporate world. CARS has undergone several updates since its development and applied to thousands of university students, schoolteachers, secondary school students as well as to business people throughout the United States (Broome and Havelka, 2002). It has also been administered to as many as 22 university students in other countries (Rosen and Weil 1995; Bradley and Russell 1997). One other reason that led to the popularity and wide acceptance of CARS is its capability to discriminate research surveys conducted regarding predictors of anxiety and performance in information technology (Aderson 1996). No sooner was the CARS instrument developed than it played an integral part in research, especially in the information technology field, such as computer anxiety (McIlroy et al. 2001). Further modification of CARS was also performed by Broome and Havelka (2002) in their computer anxiety study. It is Broome and Havelka's version of CARS that underwent further modification used to develop the new model AARS used in this accounting anxiety study.

Like with CARS, the design and format of AARS is done in such a way that it can be used for a series of questions that can specifically measure an individual's apprehension towards accounting. It is a twenty-question, five point self-rating scale instrument with the capability of assessing the accounting anxiety level of the individual (see Appendix A). Perseus survey solution software was used in developing AARS into a web-based instrument (see http://atc.bentley.edu/perseus/surveys/Ac_Anxiety.htm). The web-based AARS provides a convenient way of responding to a series of statements by the participants such as "the challenge of accruals and deferrals in adjusting entries," to determine their level of anxiousness from a scale of $1=$ Strongly Disagree to $5=$ Strongly Agree. A total of 20 questions were designed to measure the accounting anxiety levels in such a way that ten of the questions are reverse coded. That means a score of 100 would indicate the highest level of anxiety possible, while a score of say, twenty, would be a low anxiety. Given this set-up in the model and with a maximum rating of 100, one would consider a rating in excess of 70 to mean possessing an accounting anxiety level from moderate to severe when confronted with an accounting task.

\subsection{Participants}

Prior to administering the instrument, a pilot test was conducted with a total of twenty-nine participants, comprising of two accounting faculty colleagues, two accounting practitioners, five graduate and twenty undergraduate students. These individuals evaluated the instruments' content and its understandability. The instrument was then revised based on their suggestions before it was administered. The instrument was administered towards the end of Spring 2003 to all full-time registered students of Bentley College at that time. Bentley College was chosen because it is the largest business school in New England and the first business university in the United States. A total of 1,112 students responded to the survey, indicating approximately 30 percent response rate. The academic status of the respondents consists of all undergraduate, graduate, and certificate programs from all degree majors from Accounting to those who have not yet decided on a major (Undecided). The undergraduate degree level participants ranges from freshman to senior including those doing certificate programs.

Table 1 is categorized into four panels. Panel A shows the breakdown of the participants with regard to their declared majors. Panel B indicates their degree levels with a reasonable size of representation for all levels, except for certificate program where only six responded. That is, Freshman 86, Sophomore 224, Junior 225, Senior 198, and Graduate 287. Panel C shows that 94 percent (955 out of 1,020) had some accounting work-related experience. About 74 percent (705 out of 955) had between two to five years of experience, while a third (278) had more than five years of experience. Panel D shows their composition by gender, with relatively balanced representation of 45 percent (457) male and 55 percent (569) female. 
Table 1

Breakdown of Respondents

\begin{tabular}{lr}
\hline Panel A: Classification by Major & $\mathbf{N}$ \\
Name of Major & 149 \\
\hline Accounting & 31 \\
Accounting Information Systems & 64 \\
Computer Information Systems & 83 \\
Corporate Finance and Accounting & 70 \\
Economics - Finance & 169 \\
Finance & 28 \\
Information Design and Corporate Communication & 13 \\
International Studies & 5 \\
Liberal Arts & 134 \\
Management & 30 \\
Managerial Economics & 140 \\
Marketing & 7 \\
Mathematical Sciences & 51 \\
Other & 53 \\
Undecided & 1,027 \\
Total & \\
\hline Panel B: Classification by Degree Level & $\mathbf{N}$ \\
Name of Degree Level & 86 \\
\hline Freshman & 224 \\
Sophomore & 225 \\
Junior & 198 \\
Senior & 287 \\
Graduate & 6 \\
Certificate & 1,026 \\
Total & \\
\hline Panel C: Classification by Experience & $\mathbf{N}$ \\
Type of Experience & $\mathbf{N}$ \\
\hline No Experience & 657 \\
Up to 3 Months & 659 \\
3 -6 Months & 76 \\
6 Months - 1 Year & 61 \\
1 - 2 Years & 66 \\
2 -3 Years & 113 \\
3 - 4 Years & 132 \\
Over Years & 116 \\
Total & 113 \\
& 278 \\
\hline Panel D: Classification by Gender & 1,020 \\
Gender Type & \\
\hline Male & \\
Female & \\
Total & \\
\hline
\end{tabular}




\section{Results}

One-way analysis of variance (ANOVA) was used to test each of the four hypotheses developed.

\subsection{Hypothesis Tests}

\subsubsection{Tests Of $\mathrm{H1}$}

Hypothesis 1 stated that there are higher accounting anxieties among business students majoring in less quantitative degree majors than those in more quantitative degree majors. The ANOVA results presented in Panel A of Table 2 indicates that this hypothesis is significant at the $\mathrm{p}<0.000$ level. This means that the level of accounting anxiety among business students overall differ given their academic majors. Panel B of Table 2 and Figure 1 show the descriptive statistics and the graphical presentation of accounting anxiety levels by all the majors. The significant difference in accounting anxiety vis-à-vis academic majors is consistent with similar studies where anxiety levels across dividing lines exist (Rosen and Weil 1995 and Todman 2000). In determining the level of accounting anxiety among business students, an AARS score of 70 percent and above signify a moderate to severe anxiety level. While most of the statistical results for hypothesis 1 are supported, there are some mixed findings. From the fourteen different majors, Marketing, one of the less quantitative majors (with a mean of 58.91, 90\%) has the highest level of accounting anxiety. Next to Marketing are Managerial Economics $(54.03,84 \%)$, Information Design and Corporate Communication $(62.93,82 \%)$, Management $(52.55,81 \%)$, and Economics-Finance $(52.43,80 \%)$ majors with high accounting anxiety levels. These finding supports our hypothesis 1 that students majoring in less quantitative degree disciplines will experience higher accounting anxiety levels than those in more quantitative degree majors.

Students with the least level of accounting anxiety consist of Accounting Information Systems (41.29, $61 \%)$, Mathematical Sciences (46.14,61\%), and Liberal Arts (54.40, 63\%) majors. One possible explanation for this category of majors could be that, while Accounting Information Systems and Mathematical Sciences majors may be seen to possess strong analytical, accounting and computer skills needed for accounting, Liberal Arts majors, perhaps, need not be anxious about accounting as they have little related accounting tasks to perform. Falling in the middle of the two extremes are those with moderate level of accounting anxiety. These include Computer Information Systems (51.27, 79\%), Finance (47.85, 79\%), Accounting (43.23, 73\%), Undecided (31.32, 73\%), International Studies majors (54.46, 72\%), and Corporate Finance and Accounting (47.23, 71\%) majors. It is interesting to note that Accounting and Undecided majors have the same level of accounting anxiety (73\%).

\subsubsection{Tests Of $\mathrm{H} 2$}

Hypothesis 2 stated there are higher accounting anxieties in students at their lower degree levels (i.e., freshmen and sophomore) than those at their upper degree levels (i.e., junior, senior and graduate). Hypothesis 2 assumes that the more academic experience in accounting that students have, from freshmen to seniors and to graduates, the lower the level of accounting anxiety would be due to the number of accounting courses taken. In other words, one would expect to see lower levels of accounting anxiety among upper degree levels, such as graduates and seniors, than among freshmen and sophomore business students. Panels A and B of Table 3 and Figure 2 show the ANOVA results, the descriptive statistics, and the graphical presentation of the anxiety levels respectively. Accounting anxiety among business students with different degree levels is significant overall at the $p$ $<0.000$ level. That is, there were significant differences at the .05 level between freshmen and the rest of the degree levels. Hypothesis 2, however, is not supported. At the undergraduate level, the results show the opposite directionally. The level of accounting anxiety increases as the degree level increases. That is, the lowest anxiety level resides with the freshman students, while the seniors had the highest level of accounting anxiety at the undergraduate level. This also means that the more accounting courses taken, the more anxious students become, which is contrary to what was hypothesized. Panel B of Table 3 and Figure 2 shows the mean scores and percentages respectively (Freshman, 48.95, 67\%; Sophomore, 51.45, 84\%; Junior, 52.89, 89\%; and Senior, 52.92, 90\%). At the Graduate and Certificate levels, however, the anxiety levels remain moderate $(45.55,73 \%$ and 51.17 , $78 \%$ ). The consistent increase in anxiety among undergraduate business students as their degree levels increase may be associated with the level of difficulty of accounting courses. 
Table 2

Accounting Anxiety Levels

\begin{tabular}{|c|c|c|c|c|c|}
\hline \multicolumn{6}{|c|}{ Panel A: ANOVA For Accounting Anxiety Levels By Major } \\
\hline Source & SS & df & MS & $\mathbf{F}$ & $\mathbf{P}$ \\
\hline Major & 31290.039 & 14 & 2235.003 & 22.92 & 0.000 \\
\hline Error & 98677.951 & 1012 & 97.508 & & \\
\hline Total & 129967.99 & 1026 & & & \\
\hline
\end{tabular}

\begin{tabular}{lrrr}
\hline Panel B: Descriptive Statistics Of Accounting Anxiety Levels By Major & & & \\
Groups & N & Mean & Std. Deviation \\
\hline Accounting & 149 & 43.23 & 8.74 \\
Accounting Information Systems & 31 & 41.29 & 8.40 \\
Computer Information Systems & 64 & 51.27 & 9.96 \\
Corporate Finance and Accounting & 83 & 47.23 & 8.19 \\
Economics - Finance & 70 & 52.43 & 9.87 \\
Finance & 169 & 47.85 & 10.77 \\
Information Design and Corporate Communication & 28 & 62.93 & 8.92 \\
International Studies & 13 & 54.46 & 9.90 \\
Liberal Arts & 5 & 54.40 & 9.69 \\
Management & 134 & 52.55 & 10.05 \\
Managerial Economics & 30 & 54.03 & 10.56 \\
Marketing & 140 & 58.91 & 10.42 \\
Mathematical Sciences & 7 & 46.14 & 8.23 \\
Other & 51 & 42.96 & 11.73 \\
Undecided & 53 & 51.32 & 9.38 \\
\hline
\end{tabular}

Figure 1

Accounting Anxiety Graph By Major

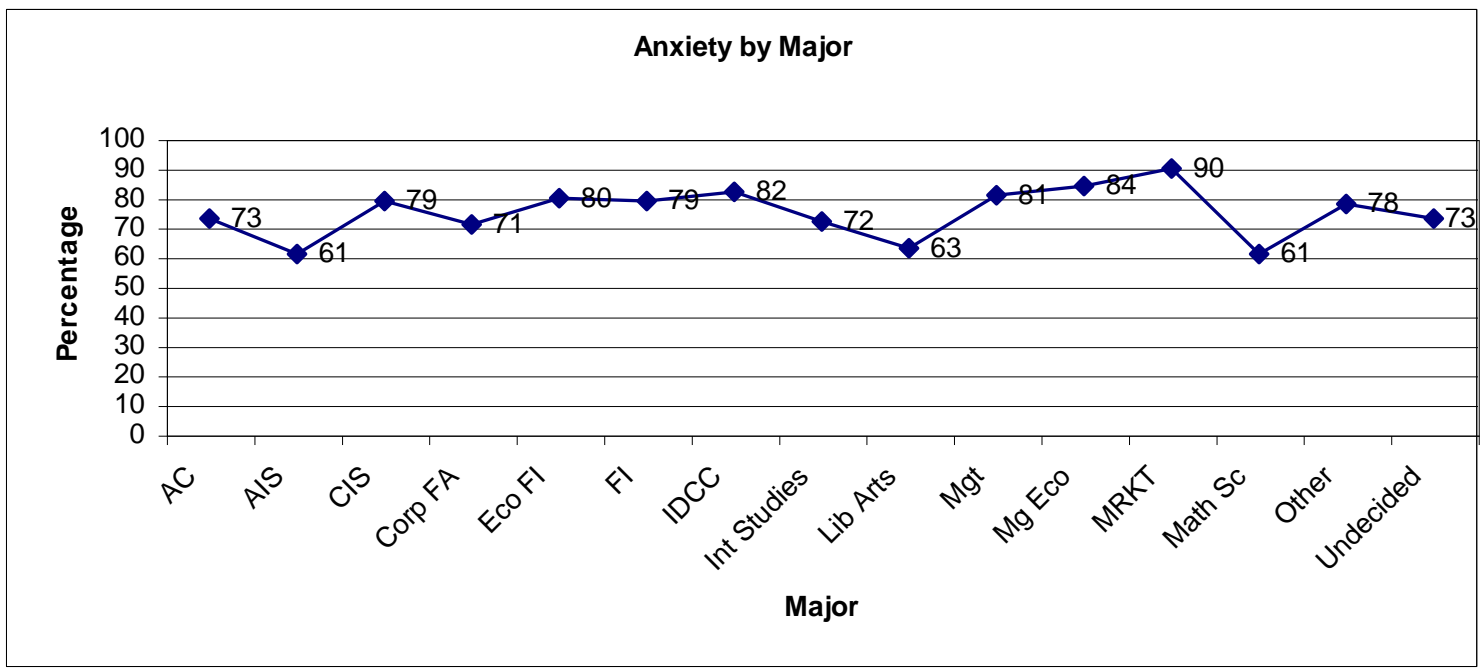

$\mathrm{AC}=$ Accounting

AIS $=$ Accounting In formation Systems

CIS $=$ Computer Information Systems

Corp FA = Corporate Finance and Accounting

Eco FI = Economics-Finance

$\mathrm{FI}=$ Finance

IDCC $=$ Information Design and Corporate Communication
Int Studies = International Studies

Lib Arts = Liberal Arts

Mgt = Management

Mg Eco = Managerial Economics

MRKT $=$ Marketing

Math $\mathrm{Sc}=$ Mathematical Sciences 
Table 3

Accounting Anxiety Levels

\begin{tabular}{lccccc}
\hline Panel A: ANOVA For Accounting Anxiety Levels By & Degree Level & & \\
Source & SS & df & MS & F & P \\
\hline Degree Level & 9790.046 & 5 & 1958.009 & 16.68 & 0.000 \\
Error & 119745.27 & 1020 & 117.397 & & \\
Total & 129535.32 & 1025 & & &
\end{tabular}

\begin{tabular}{|c|c|c|c|}
\hline \multicolumn{4}{|c|}{ Panel B: Descriptive Statistics Of Accounting Anxiety Levels By Degree Level } \\
\hline Groups & $\mathbf{N}$ & Mean & Std. Deviation \\
\hline Freshman & 86 & 48.95 & 9.13 \\
\hline Sophomore & 224 & 51.45 & 11.29 \\
\hline Junior & 225 & 52.89 & 11.32 \\
\hline Senior & 198 & 52.92 & 11.32 \\
\hline Graduate & 287 & 45.55 & 10.10 \\
\hline Certificate & 6 & 51.17 & 15.20 \\
\hline
\end{tabular}

Figure 2

Accounting Anxiety Graph By Degree Level

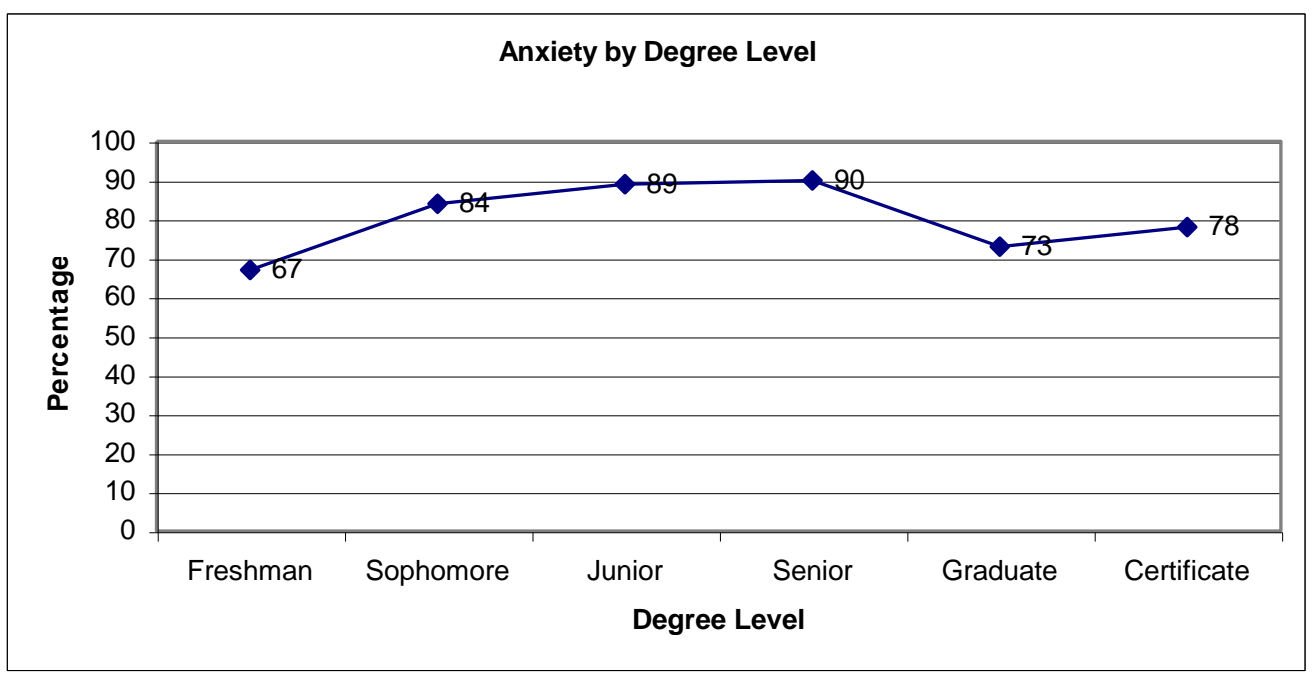

\subsubsection{Tests Of $\mathrm{H3}$}

Hypothesis 3 stated that there are higher accounting anxieties among business students with less years of work experience or exposure than those with more work experience or exposure. As noted earlier in the literature review, anxiety is treatable (Chu and Spires 1991) and, therefore, one would expect to see those with accounting related work experience or exposure to have lower level of accounting anxiety. Therefore, the more the experience or exposure students have, the lower the level of accounting anxiety. Ranges in months and years were used to identify and gather the duration of experience from No Experience to Over 5 Years. Panels A and B of Table 4 and Figure 3 presents the ANOVA results, the descriptive statistics, and the graph respectively. The difference in accounting anxiety among business students with different years of work experience is also significant at $\mathrm{p}<0.018$ (at the .05 level), in years of work related experience between $<3$ months and $>5$ years. However, the descriptive statistics (see Panel B of Table 3) show an opposite result to hypothesis 3 . That is, H3 is not supported. The category of people with the lowest accounting anxiety level was those who had no experience and those with experience not 
exceeding 3 months. That is, those with the least experience are associated with the least accounting anxiety (No Experience, 51.00, 76\% and Up to 3 Months, 52.78, 76\%). Similarly, those with the most experience (> 3 years) are associated with the highest level of accounting anxiety ( $3-4$ years, $52.29,90 \%$; $4-5$ years, $47.88,84 \%$; and $>5$ years, $49.44,81 \%)$ respectively. Observing the level of experience vis-à-vis the accounting anxiety levels from Figure 3, there appear to be no clear cut linear relationship between those who had three months of experience or more. Overall, irrespective of the level of work experience (or no work experience at all), all respondents indicate a moderate to severe level of accounting anxiety when it comes to accounting task related experience. This finding seems to be consistent with the computer anxiety study where experience was found as not a good indicator of anxiety (Broome and Havelka 2002).

Table 4

Accounting Anxiety Levels

\begin{tabular}{lccccc}
\hline $\begin{array}{l}\text { Panel A: ANOVA For Accounting Anxiety } \\
\text { Source }\end{array}$ & SS & df & Evels By Experience & & \\
\\
\hline Experience & 2298.063 & 8 & 287.268 & 2.32 & P \\
Error & 125466.66 & 1011 & 124.102 & & .018 \\
Total & 127764.73 & 1019 & & &
\end{tabular}

\begin{tabular}{|c|c|c|c|}
\hline \multicolumn{4}{|c|}{ Panel B: Descriptive Statistics Of Accounting Anxiety Levels By Experience } \\
\hline Groups & $\mathbf{N}$ & Mean & Std. Deviation \\
\hline No Experience & 65 & 51.00 & 10.25 \\
\hline Up to 3 Months & 76 & 52.78 & 9.63 \\
\hline 3-6 Months & 61 & 52.80 & 11.21 \\
\hline 6 Months -1 Year & 66 & 49.92 & 10.32 \\
\hline $1-2$ Years & 113 & 49.59 & 11.68 \\
\hline $2-3$ Years & 132 & 49.89 & 10.72 \\
\hline $3-4$ Years & 116 & 52.29 & 1.74 \\
\hline $4-5$ Years & 113 & 47.88 & 11.80 \\
\hline Over 5 Years & 278 & 49.44 & 11.33 \\
\hline
\end{tabular}

Figure 3

Accounting Anxiety Graph By Experience

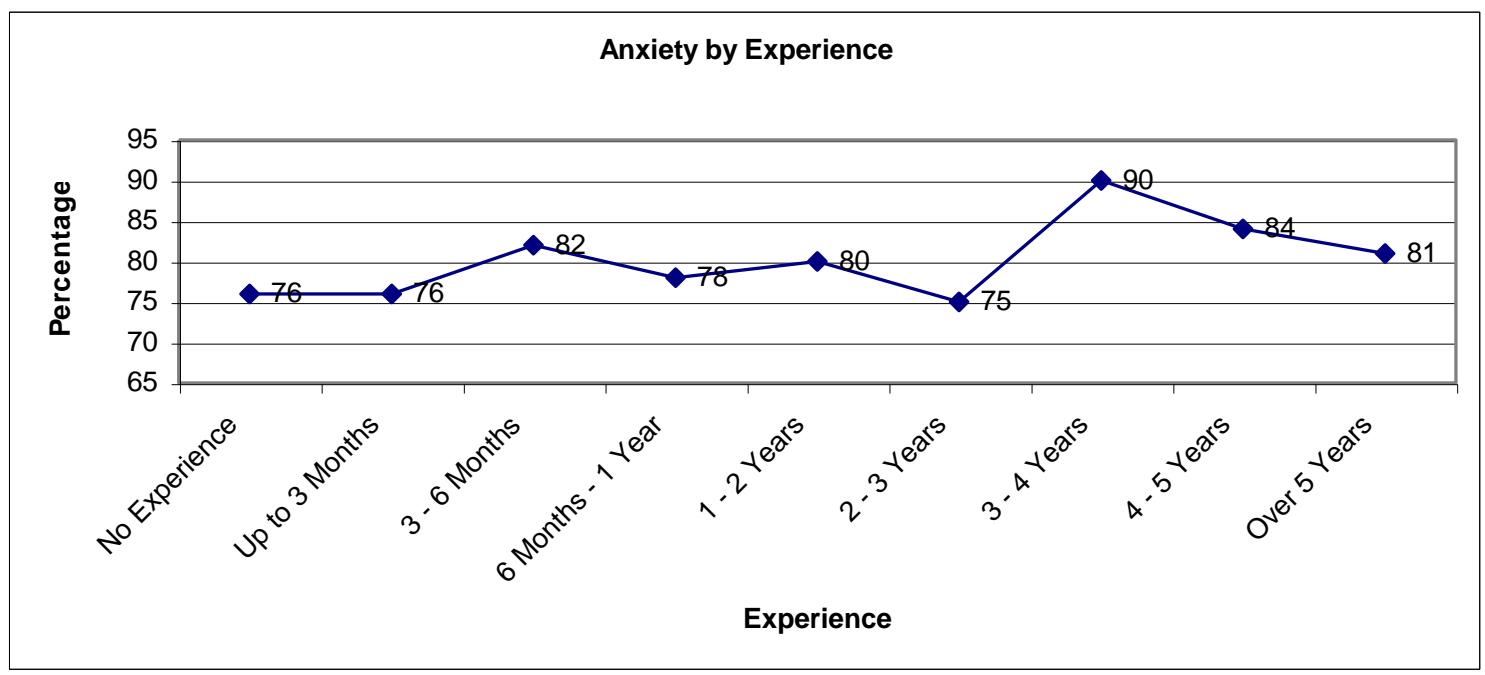




\subsubsection{Tests Of $\mathrm{H4}$}

Hypothesis 4 stated that there are lower levels of accounting anxiety in female than in male business students. This hypothesis was partly based on prior research results, which consistently found that differences in anxiety levels do exist between male and female students where male students show a significantly lower anxiety levels than female students. Also, like in mathematics, computers, and chemistry, accounting is seen more as quantitative or analytical business discipline, which may appeal more to male students than to their female counterparts. However, recent study of computer anxiety by Broome and Havelka (2002) found the opposite to be the case, indicating that female students have "caught up" with their male counterparts with regards to technology. Also, female students in this study outnumbered their male counterparts, which could mean that female students are becoming more business oriented and therefore less likely to experience higher accounting anxiety levels than their male counterparts. Panels A and B of Table 5 and Figure 4 presents the results of H4. The mean anxiety scores (see Panel B) for both male and female students are 40.26 and 36.85 respectively. The results indicate that differences in accounting anxiety among male and female business students are significant $(\mathrm{p}<0.000)$. This means that, unlike with Broome and Havelka's (2002) recent study, male business students show a lower accounting anxiety level than their female counterparts. While hypothesis 4 is not supported, this finding is also consistent with earlier research results related to anxiety between male and female (Todman 2000 and McIlroy et al. 2001). However, in this study, both male and female students show significantly high accounting anxiety levels. Figure 4 shows the graphical presentation of the gender differences in percentages (Male, $84 \%$ and Female, 90\%). The findings of this result still confirm earlier studies, which translate into the popular belief that the gap in gender-biased roles in the world of business is resident in the accounting profession.

Table 5

Accounting Anxiety Levels

\begin{tabular}{|c|c|c|c|c|c|}
\hline \multicolumn{6}{|c|}{ Panel A: ANOVA For Accounting Anxiety Levels By Gender } \\
\hline Source & SS & df & MS & $\mathbf{F}$ & $\mathbf{P}$ \\
\hline Gender & 2315.748 & 1 & 2315.748 & 18.59 & .000 \\
\hline Error & 127529.93 & 1024 & 124.541 & & \\
\hline Total & 129845.68 & 1025 & & & \\
\hline
\end{tabular}

\begin{tabular}{lccc}
\hline \multicolumn{3}{l}{ Panel B: Descriptive Statistics Of Accounting Anxiety Levels By Gender } & \\
Groups & N & Mean & Std. Deviation \\
\hline Male & 457 & 48.54 & 10.55 \\
Female & 569 & 51.56 & 11.26 \\
\hline
\end{tabular}

Figure 4

Accounting Anxiety Graph By Gender

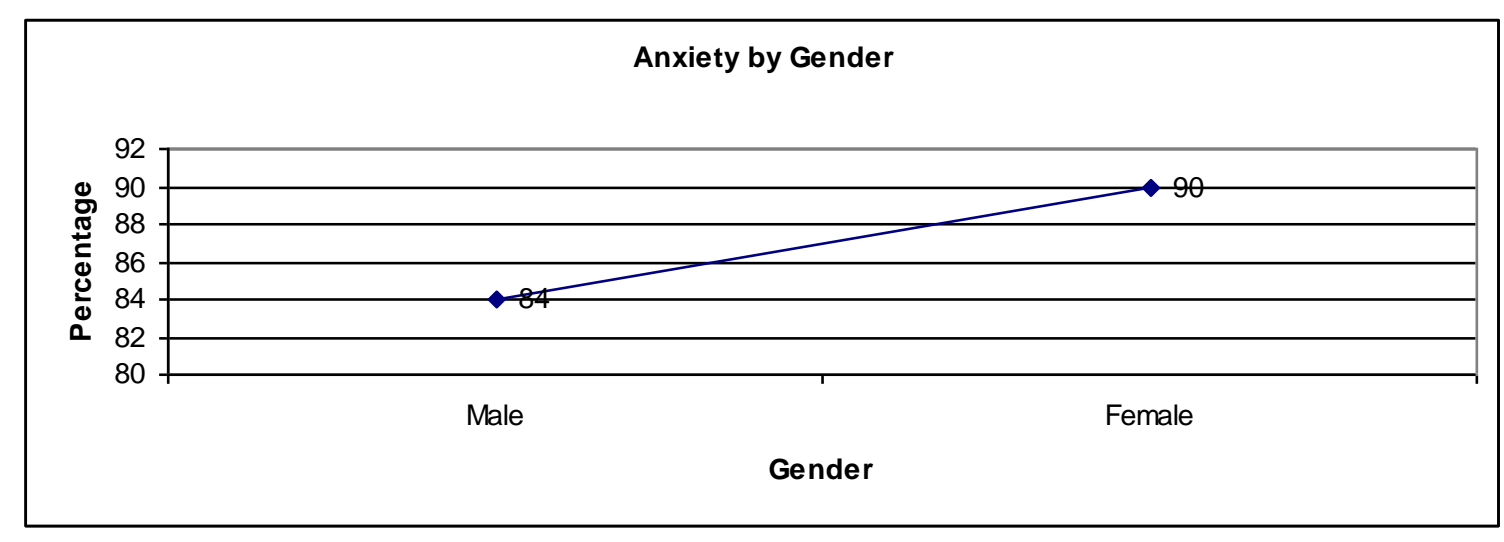




\subsection{Discussion And Conclusions}

Earlier studies about anxiety in related fields (this being the first in accounting) linking anxiety with students have been equivocal. Several conflicting results were noted in the literature review, which were both positive and negative when linking anxiety with academic disciplines, courses taken, task related experience, and gender. Overall, analyses of the data in this study confirmed all four hypotheses that there are positive relationships between accounting anxiety and business students. The results show a statistically significant difference in all four tests. That is, about 79 percent of all the business students who participated in the survey had accounting anxiety ranging from moderate $(71 \%)$ to severe $(90 \%)$. Within this 79 percent category, Marketing students experience accounting anxiety the most (90\%), and this is followed by Managerial Economics (84\%), Information Design \& Corporate Communications (82\%), Management (81\%), and Economics-Finance (80)\%). Those who experience the least accounting anxiety (below the moderate level of $70 \%$ ) are Accounting Information Systems (61\%), Mathematical Sciences (61\%) and Liberal Arts (63\%) students. Those who fall in the middle (71\% - 79\%) consist of Accounting, Finance, Corporate Finance and Accounting, Computer Information Systems, and International Studies majors.

One other interesting finding from this study is the fact that there is a linear relationship between accounting anxiety and students' degree levels. That is, the higher the students' degree levels (freshman, sophomore, junior and senior), the higher their level of accounting anxiety $(67 \%, 84 \%, 89 \%$ and $90 \%$ respectively). This is true only at the undergraduate level, but neither at the graduate nor the certificate level. Although the accounting anxiety levels at both the certificate and graduate levels are moderate to high (73\% and 78\%), they are comparatively lower than the undergraduate students (except for the freshman level). Also of interest in this study is the significant, but negative, association between accounting anxiety and work experience. Those who had three to five years of work experience are the most anxious with accounting anxiety. Overall, accounting anxiety is significant with or without experience, ranging from 75 percent to 90 percent. Also, unlike in other studies, this study found support for genderbased differences in accounting anxiety, with male business students exhibiting lower levels of accounting anxiety than their female counterparts.

This study, therefore, should be of interest to many including researchers, educators, university administrators, and the business community in a number of ways. For example, this may draw the attention of many, especially the Accounting Education Change Commission who is interested in ensuring that introductory accounting is more attractive in order to encourage and motivate students to become accounting majors. Also, the findings from this research could be used to direct attention towards dealing with anxiety related issues to business students taking accounting courses. This would, in turn, help in the development of course curriculum and improve students' learning. Since this study is the first in accounting that looked at accounting anxiety, it opens the door for more research into this area to see if there is some consistency with this study or a consequence of differences in geographical location, research model (AARS), or some other factors.

\section{References}

1. Abouserie, R. (1994). "Sources and Levels of Stress in Relation to Locus of Control and Self-Esteem in University Students", Educational Psychology, 14(3): 323-330.

2. Accounting Education Change Commission (AECC). 1990. "Objectives of Education for Accountants: Position Statement Number One", Issues in Accounting Education, 5(2): 307-312.

3. 1996. Positions and Issues Statements of the Accounting Education Change Commission. Sarasota, FL: American Accounting Association.

4. Albrecht, W. S., and R. J. Sack. (2000). "Accounting Education: Charting the Course Through a Perilous Future", Accounting Education Series, Volume No. 16. A Joint Project of: AAA, AICPA, IMA, Arthur Andersen, Deloitte \& Touché, Ernst \& Young, KPMG, and PricewaterhouseCoopers.

5. Ameen, E. C., D. M. Guffey., and C. Jackson. (2002). "Evidence of Teaching Anxiety Among Accounting Educators", Journal of Education for Business, September/October, 16-22.

6. Arendale, D. (1994). "Understanding the Supplemental Instruction Model", New Directions for Teaching and Learning, 60: 11-21. 
7. Baldwin, B., and R. Ingram. (1991). "Rethinking the Objectives and Content of Elementary Accounting", Journal of Accounting Education, Spring, 1-14.

8. Bowen, C. W. (1999). "Development and Score Validation of a Chemistry Laboratory Anxiety Instrument for College Chemistry Students", Educational and Psychological Measurement, 59(1): 171-185.

9. Bozionelos, N. (1997a). "Psychology of Computer Use: XLIV Computer Anxiety and Learning Style", Perceptual and Motor Skills, 78: 753-754.

10. Broome, T. and Havelka, D. (2002). "Determinants of Computer Anxiety in Business Students", The Review of Business Information Systems, 6(2): 9-16.

11. Britton, B. K., and A. Tesser. (1991). "Effects of Time-Management Practices on College Grades", Journal of Educational Psychology, 83(3): 405-410.

12. Buckley, P. A., and S. C. Ribordy. (1982). "Mathematics Anxiety and the Effects of Evaluative Instructions on Math Performance", Paper Presented at the Midwestern Psychological Association, Minneapolis, MN.

13. Burkett, W. H., D. M. Compton., and G. G. Burkett. (2001). "An Examination of Computer Attitudes, Anxieties, and Aversions Among Diverse College Populations: Issues Central to Understanding information Sciences in the New Millennium", Information Science, 3(4): 77-85.

14. Cambell, R. L., and L. W. Svenson. (1992). "Perceived Level of Stress Among University Undergraduate Students in Edmonton, Canada", Perceptual and Motor Skills, 75(2): 552-554.

15. Carveth, J. A., T. Gesse., and N. Moss. (1996). "Survival Strategies for Nurse-Midwifery Students", Journal of Nurse-Midwifery, 41(1): 50-54.

16. Etter, E. R., S. L. Burmeister., and E. J. Randal. (2000). "Improving Student Performance and Retention Via Supplemental Instruction”, Journal of Accounting Education, 18: 355-368.

17. Fairbanks, P. J. (1992). "Treating Mathematics Anxiety: The Optional Contract", The Mathematics Teacher, 85(6): 428-430.

18. Fisher, R. T. (2001). "Role Stress, The Type A Behavior Pattern, and External Auditor Job Satisfaction and Performance", Behavioral Research In Accounting, 13: 143-170.

19. Furner, J. M., and B. T. Berman. (2003). "Math Anxiety: Overcoming a Major Obstacle to the Improvement of Student Math Performance", Childhood Education, Spring, 170-174.

20. Heinssen, R. K. J., C. R. Glass, and L. A. Knight. (1987). "Assessing Computer Anxiety: Development and Validation of the Computer Anxiety Rating Scale", Computers in Human Behavior, 3(1): 49-59.

21. Humphreys, M. S., and W. Revelle. (1984). "Personality, Motivation, and Performance: A Theory of the Relationship Between Individual Differences and Information Processing", Psychological Review, 91: 153-184.

22. Jackson, S., and R. Schuler. (1985). "A Meta-Analysis and Conceptual Critique of Research on Role Ambiquity and Role Conflict in Work Settings", Organizational Behavior and Human Decision Processes, August, 16-78.

23. McIlroy, D., B. Bunting, K. Tierney and M. Gordon. (2001). "The Relation of Gender and Background Experience to Self-Reported Computing Anxieties and Cognitions", Computers in Human Behavior. 17: 21-33.

24. National Council of Teachers of Mathematics. (1989). Curriculum and Evaluation Standards for School Mathematics. Reston, V. A., Author.

25. Preiss, R. W., L. R. Wheeless, and M. Allen. (1990). "Potential Cognitive Processes and Consequences of Receiver Apprehension: A Meta-Analytic Review”, Journal of Social Behavior and Personality, 5(2): 155-172.

26. Stone, D. N., V. Arunachalam, and J. S. Chandler. (1996). "Cross-Cultural Comparisons: An Empirical Investigation of Knowledge, Skill, Self-Efficacy and Computer Anxiety in Accounting Education", Issues in Accounting Education, 11(2): 345-376.

27. Towell, E. R., and J. Lauer. (2001). "Personality Differences and Computer Related Stress in Business Students", Mid-American Journal of Business, 16(1): 69-75.

28. Venkatesh, V. (2000). "Determinants of Perceived Ease of Use: Integration Control, Intrinsic Motivation, and Emotion into the Technology Acceptance Model”, Information Systems Research, 11(4): 342-365.

29. Williams, D. (1991). "The Challenge of Change in Accounting Education", Issues in Accounting Education, Spring, 126-133. 


\section{Appendix: Survey Instrument}

1. The challenge of learning accounting is exciting.

2. I feel that accounting is a necessary tool in both educational and work settings.

3. I have avoided accounting courses because they are unfamiliar and somewhat intimidating to me.

4. I have difficulty in understanding how accounting systems work.

5. I feel that understanding accounting will make me a more productive individual.

6. I feel insecure about my ability to prepare, analyze and interpret financial statements.

7. I look forward to preparing, analyzing and interpreting financial statements.

8. I do not think I would be able to learn the accounting information systems.

9. I am confident I can learn the accounting skills.

10. Anyone can learn to apply the accounting information systems if they are motivated and practice.

11. Learning accounting is a new skill, the more you practice the better you become.

12. I am afraid that if I begin to use accounting software I will become dependent on them and lose some of my reasoning skills.

13. I am sure that with time and practice I will be as comfortable working with the accounting software as I am working with basic word processing software.

14. I feel that I will be able to keep up with the advances happening in the accounting profession.

15. I feel apprehensive about having to pass the CPA examinations in order to practice or do well in the profession.

16. I feel apprehensive about using accounting systems.

17. It scares me to think that I could cause all the financial statements to be wrong by committing an error of principle.

18. I hesitate to use accounting software for fear of making mistakes that I cannot correct.

19. One has to be a genius to understand all the accounting transactions and adjusting entries that go into preparing an accounting cycle.

20. If given the opportunity I would like to learn about and use accounting software. 